\title{
ОНТОЛОГИЯ КУЛЬТУРЫ: ПРЕДПОСЫЛКИ СИНЕРГЕТИЧЕСКОГО АНАЛИЗА
}

\author{
И.А. Донникова
}

Что есть культура? Этот вопрос для философско-культурологической мысли обрел, по-видимому, статус «вечного». Исследование феномена культуры сопровождается открытием новых, все более глубоких связей культуры и человека и вновь требует объяснения их органичности и взаимозависимости.

Особую актуальность исследование культуры обретает в настоящее время, когда в постнеклассической науке формируется новое предметное поле-самоорганизуюшиеся живые системы с набором определенных характеристик, свойств, особенностей поведения и развития. Различные срезы и уровни социоприродной реальности исследуются как сложные, способные к самоорганизации среды и системы. Но из этой реальности словно «выпадает» феномен культуры. В лучшем случае культура остается востребованной в качестве особого социального механизма, причем «локального» действия, позволяющего объяснить функционирование более значимых с точки зрения социальности сфер человеческой жизни.

На наш взгляд, новая методологическая программа, формирующаяся на основе синергетики, не только эвристична для философскокультурологического знания, но и крайне необходима. Постоянно возрастающее количество определений культуры свидетельствует об исчерпанности традиционных подходов, о назревшей потребности перехода к новому уровню систематизации и интерпретации культурологического знания. Подобный плюрализм оставляет открытым вопрос о сущности и назначении культуры.

Актуальні проблеми духовності

(Відп. ред.: Я.В. Шрамко)

Кривий Ріг (2007), 400-413 
Применение синергетической методологии в философско-культурологических исследованиях не следует рассматривать исключительно как следование научным нововведениям. Оно основано на реальной возможности диалога философии и синергетики, на выявлении в социокультурном бытии «синергетических» параметров. В связи с этим научный интерес представляет не только современное культурфилософское знание, но и сам процесс его развития, в котором выявляются «синергетические» характеристики культуры. В данной статье предпринята попытка провести предельно общий анализ этого процесса, который может стать основанием для синергетического анализа культуры.

Безусловно, любая историческая ретроспектива всегда содержит опасность всякого рода «натяжек» и «подтасовок». Однако в эволюции познания очень часто новое есть хорошо забытое старое. Однажды возникшие идеи не исчезают бесследно. По тем или иным причинам они оказываются «забытыми» или невостребованными в породившем их историческом времени и скрываются под напластованиями более поздних идей. В определенной степени синергетику можно отнести к таким знаниям. Как отмечает Е.Н. Князева, синергетика «парадоксальным образом возвращает нас к тем идеям, которые имеют тысячелетнюю историю, заставляет нас переоткрыть, по-новому осмыслить то, что составляет сокровищницу древней мудрости» $[3$, с.9].

Мировоззренческие изменения, связанные с утверждением синергетики, побуждают переосмысливать историю различных идей и теорий, выявляя закономерности их появления и трансформации. Уже в древних космогонических построениях, мифологических представлениях Востока и Запада присутствовали близкие синергетическому видению модели мироописания. По словам Л.Д. Бевзенко, «все эти миры человеческого опыта при внимательном рассмотрении опираются на нелинейную, близкую синергетической логику видения динамики событий, в которой не поляризуются такие вещи как порядок и хаос, закономерность и случайность, предзаданность и управляемость» $[1$, c. 25].

Мировоззренческие параллели синергетических представлений прослеживаются также в научных, философских, культурологических теориях, начиная с древнегреческих и древнеримских форм осмысления мира и заканчивая современными формами западноевропейской культуры.

Представления о культуре изначально выражали основную идею синергетического миропонимания - целостности человеческого бытия 
и мира. По мере развития познания понятие «культура» менялось, расширялись и углублялись его значения, тем не менее, во всех значениях сохранялся его исходный смысл - культура выступала способом поддержания изначальной целостности человека и мира.

Само понятие культуры зарождается в мифологических представлениях о самостановящемся мировом порядке, возникающем из хаотичности мира. Древнегреческие формы осмысления мира двигаются от Хаоса Гесиода и Океана Гомера к упорядоченному космосу (включающему природу и человека) Пифагора и Гераклита, Аристотеля и Плотина. Формируется представление о «рукотворном» порядке, жизни «по установлению», которой предстояло получить совокупное обозначение «культура». В космоцентричном мировоззрении возникают две основные идеи, постоянно возрождающиеся в европейской философской традиции: культура - технология, способ создания человеческого бытия и продолжение природного порядка, воссоздаваемого человеком в «рукотворном» мире.

В понимании древних греков «номос»-жизнь по установлению, создается человеком через подражание природе посредством его технических умений, навыков, обретаемых, прежде всего, через воспитание. В космоцентричном мировоззрении эллинов «номос» противостоит первичному хаосу как упорядоченное бытие, сконцентрированное на человеке. Хаос в мировоззрении древних греков становится своеобразной «точкой отсчета» для онтологических философских построений, причем представления о нем меняются в зависимости от того, как античные мудрецы понимают сущность мирового порядка, в чем видят основания его единства.

Так, у пифагорейцев представления о мировой гармонии связаны с рациональными числами, в то время как иррациональные выступают образом хаоса, нарушением гармонии. Анаксимен образ первичного хаоса представляет через апейрон - беспредельное, порождающее противоположности, которые лежат в основе гармонии мира. Соединения атомов у Демокрита также олицетворяют совместную гармонизацию, естественное подчинение параметру порядка. Наиболее явно идея организованности бытия выражена в учении Аристотеля о форме и материи. Бытие возникает, выявляется как результат взаимодействия исходного, предельно неорганизованного начала (материи) и силы, энергии, способной организовать материю в вещь (формы).

Постижение «рукотворного» порядка происходит через осмысление «фьюзиса» - упорядоченного естественного бытия, возникшего из хаоса. По словам А.С. Богомолова, для древних греков природа сочетает 
в себе генетическую, субстанциональную и управляющую функции и предстает живым, подвижным, не нуждающимся во внешних привнесениях целым [2, с. 40].

Единство с природой выражается в «любовании космосом», рождая ключевые понятия античной культуры - красоту, меру, гармонию, - a также в умозрении, формирующем рациональное познание.

Однако уже в начальный период развития античной философии поиск первоначала, определяющего Единое, меняет представления о природе, которая все более превращается в «материал». Культура как часть природы, также тяготеет к ее вещественному, телесному воплощению, в центре которой - человек как мера всех вещей.

Поздняя античность еще сохраняет представления об изначальной целостности мира, хотя уже и она далека от древнейших мифологических воззрений, согласно которым «все происходит само собой», «все подобно всему», «как наверху, так и внизу» (Гермес Трисмегист). По мере становления рационального познания мир в сознании греков неизбежно распадается на части, дифференцируется. В структурированном «рукотворном мире» обособляется индивидуальное бытие (Эпикур, стоики, скептики), еще подчиняющееся макрокосмосу, но уже претендующее на автономность. Природа - теперь уже не образец для человека, а скорее отражение самого человека. По словам А.Ф. Лосева, поздние античные мыслители уже на природу и мир переносят целую совокупность внутренних способностей человеческого субъекта [6, с. 738].

Разделив мировой порядок на природу и культуру, выделив в нем человека и государство, античные мудрецы пытались найти новые основания их целостности. Человек утратил непосредственную принадлежность к Единому, соприкоснувшись через познание с бесконечными множественными мирами-ступенями, образованными в результате эманации Единого. Отныне человек навсегда принадлежал «царству множества и разделенности», дающему искаженный образ высшего мира (Плотин).

Отдаляясь, Единое все менее доступно рациональному познанию. Оно уступает место экзегезе, посредством которой раскрываются смыслы трансцендентного бытия. Экзегеза становится новым способом нахождения священного основания единства человека и мира. Этим единством выступает Бог. «Рукотворный мир» становится жизнью «по установлению» Бога, который выступает как главный «регулятивный принцип средневекового мира» [12, с.36].

Бог становится объективным и абсолютным критерием всего чело- 
веческого существования. Толкование, созерцание Откровения-Знания сузило «культурный космос» античности до единообразия Посредника между человеком и миром. Отныне в представлении человека мир структурируется Богом, который сообщает ему смысл, наполняет божественной символикой.

Необозримый в вертикальном срезе мир меняет представления человека о мировом порядке и его внутренних источниках. Порядок«верх», обожествляется, одухотворяется и олицетворяет высшие, абсолютные качества - Благо, Истину, Добро, Красоту. Хаос-«низ», демонизируется, исключая веру как основной гармонизирующий фактор. В «вертикали» средневекового мышления культура в ее античном понимании исчезает. Отныне не человек-мера всех вещей, а «верх» и «низ» определяют меру всему. «Вещи воспринимаются и постигаются не столько в своем контексте, сколько в той вертикали, которая выступает как смыслопорождающая» [8, с. 455].

Экзегетика как способ постижения сущности божественного требует особого эмоционального напряжения, душевных усилий. Общение с Богом наделяет человеческую жизнь психологизмом и, как следствие, формирует символическое сознание средневековья. Как отмечает Л.Н.Столович, «уже на заре средневековой философии появилась своеобразная семиотика - учение о знаках и символах» [12, с. 42]. Развернутую теорию знака дает Августин, воззрения Псевдо-Дионисия Ареопагита включают учение о символе, одновременно толкуемом и как образ.

Символ структурирует не только духовный мир человека, он охватывает все средневековое социальное пространство, отражая предопределенность человеческого бытия божественным провидением. Вместе с тем, символ становится предтечей поиска и собственно человеческих смыслов бытия. Неслучайно через несколько столетий философия, обращенная к человеческой субъективности, вновь возвратится к символу, пытаясь найти связь индивидуального сознания с объективной реальностью.

Граница между хаосом и гармонией, Богом и дьяволом проходит через человеческую душу, которая является полем битвы добра и зла. Человек находится на границе дуального мира, устремлен к Богу (порядку), но доступен и для дьявола (хаоса). Только через веру, преодолевая свою слабость и беспомощность, человек принимает дуальность хаотического и страшного мира. «Через хаос, через абсурдность, через чудовищность жизни, как солнце через тучи, глянет око Божье. Бога, который имеет личность, и личность, отображенную в каждой 
человеческой личности» [7].

Противопоставляя античному космоцентризму теоцентризм, средневековые мыслители, тем не менее, также ищут идеал человека, находящегося в гармонии с миром. Разница определяется лишь тем, что античный мир мыслится гармоничным изначально, средневековый же существует в осознании «потерянного рая». Отсюда и качественно иные представления о способах восстановления утраченной гармонии - в Боге и через постижение Бога. Средневековье, стремясь к преодолению телесной замкнутости человека, культивирует неисчерпаемость, бездонность души, устремленной к Богу. В синергии человека и Бога сохраняется миропорядок.

Восприятие мира сквозь призму человеческой субъективности усиливается в эпоху Возрождения, пантеистическое мировоззрение которой реабилитирует и человека с его творческими возможностями, и культуру в ее античном понимании. «Ценность и достоинство человека заключаются в его сердце и в его воле; именно здесь- основа его подлинной чести», - пишет Монтень в «Опытах» [9, с. 78-79].

Символический мир средневековья трансформируется в художественно-целостные образы реальности, которые способствуют постижению и упорядочиванию мира через творчество человека. Культура осмысливается уже как результат такого постижения и упорядочивания - как совокупность продуктов творческой деятельности человека, такой же разносторонней и разнообразной, как и сам человек.

Вместе с тем, чем ярче проявления творческих потенций человека, тем ощутимее его дисгармония с миром. Монтень пишет: «Наше устройство - и общественное, и личное - полно несовершенств, в отличие от природы, в которой ничто не бесполезно, даже сама бесполезность» $[10$, с. 8]. Уже на исходе Возрождения человеческое познание все более обращается к изучению естественного окружения человека природы, венцом которой человек себя провозглашает.

Совершенство человека, дающее ему право претендовать на особую роль в природе, видится философами Нового времени в мышлении, способности к рациональному познанию. Б. Паскаль возвышает человека над Вселенной, ибо уничтожаемый дуновением ветра или каплей воды «мыслящий тростник», осознает расставание с жизнью. Декарт утверждает, что основное совершенство человека состоит в том, что он обладает свободой воли. Но воля также является источником ошибок и заблуждений, если выходит за пределы разума (см. [12, с. 51]).

Становление классического естествознания и формирование классического типа научной рациональности со свойственными им внима- 
нием к объекту, стремлением получить объективно-истинное знание о мире, сопровождается исключением всего, что относится к субъекту и процедурам его познавательной деятельности. Механистическая картина природы, а затем общенаучная картина мира, детерминистские и рационалистические установки сознания отражают линейные представления о мире, в контексте которых складывается и понимание культуры.

В рамках рационалистического мировоззрения происходит критическое переосмысление идей предшествующей философии с позиций самозаконодательного «естественного разума». В поиске путей очищения разума от различного рода предрассудков возникает проблема способа применения познавательных способностей человека, известная как проблема метода.

$\Phi$. Бэкон разрабатывает последовательную программу очищения человеческого разума от всякого рода антропоморфизма - родового, социального, исторического, индивидуального; конкретизация «дезантропоморфизации» познания происходит в работах Т. Гоббса и Б. Спинозы. К числу факторов, мешающих познанию, причислены и культурные предрассудки (Р. Декарт), которые замутняют разум и препятствуют самостоятельному поиску истины; следование культурной традиции означает признание чужого авторитета и отказ от собственного разума и свободы (Дж. Локк).

Несмотря на негативное отношение к традиции (как носителю чужой субъективности) в методологических изысканиях философов XVII века обнаруживается «культурологический» смысл. На первый план в культуре выходит ее воспитательная функция, в данном случае прилагаемая к разуму человека. Главная задача видится в культивировании разума, то есть развитии его посредством обучения и знаний. Культура, таким образом, рассматривается не как объект, а как качество ума человека, сформированное его целенаправленной организующей деятельностью.

Можно говорить об определенном сужении значения этого понятия в рационалистическом сознании Нового времени. Из способа «встраивания» человека в мир культура трансформируется в инструмент совершенствования человеческого разума, «растворяется» в разумности человека и создаваемой им искусственной общественной организации. Отождествление культуры и знания приводит к тому, что социальный порядок - воплощение разумной деятельности людей, обозначается чаще всего понятиями «государство» и «цивилизация» и отождествляется, прежде всего, с правовым порядком, который призван про- 
тивостоять как хаосу анархии, так и произволу деспотизма. Кроме того, цивилизация служит обозначением не только искусственного и разумного, но и должного, правильного, единственно возможного способа существования человека. В культуре же, как еще одном обозначении «искусственного», по заключению Т. Гоббса, нет необходимости.

Тем не менее, в Новое время намечается противоречие, которое определило культурфилософскую проблематику следующих столетий: между культурным как индивидуально-личностным (субъектным) и разумным как всеобще-родовым. Отстаивая идею свободной, разумной личности, просветительский индивидуализм, при этом, акцентирует внимание на надындивидуальном начале, преобразующем человека, - обществе и государстве. Разумные основы жизненного устройства означали, прежде всего, коллективные формы организации жизни, подчиняющие себе индивидуальные интересы и потребности. Между тем, познание человеческой субъективности не могло произойти через ориентацию на коллективного субъекта, общество и человечество в целом. Именно поэтому культурологические идеи, ставшие основой формирования философии культуры XVIII-XIX веков, разрабатывались в рамках философских направлений и систем, в той или иной степени представляющих альтернативу крайнему рационализму и механицизму: в «моральной философии» английского Просвещения (Шефтсбери, Ф.Хатчесон, Д. Юм), в философии истории Ж.-Ж.Руссо, Дж. Вико, И.Г. Гердера. Поднимая вопросы, характерные для Просвещения, философы стремились к целостному восприятию культуры, ее различных форм (морали, религии, права, языка, традиций и т. д.) и человечества как культурной общности.

Постепенно осуществляется переход от негативного отношения к исторической традиции к формированию «философской истории». Тема истории, актуальная в философии, становится историей культуры, в контексте которой осмысливаются проблемы свободы, справедливости, сущности человека и познания, взаимодействие природы и культуры. В формирующейся философии культуры возникают идеи о многообразии и вариативности исторического процесса, его необратимости, самоценности исторических эпох. По мнению Гердера, история культуры - это плюралистичная история, в каждой точке которой человечество как бы веерообразно расходится в разных направлениях в соответствии с желаниями и объективными возможностями, и именно это многообразие реализованных вариантов обеспечивает внутреннее богатство культуры взаимосвязанного человечества. «Нашему человеческому роду потрясения нужны, как волны - водной глади, для того 
чтобы озеро не превратилось в болото» [4, с. 234].

Именно от Гердера берет начало одна из важнейших идей философии истории и культуры-мысль о том, что любое культурное образование, возникающее в истории, уникально, индивидуально. Культура если и не осознается еще как «субъектный» аспект истории, то рассматривается как связанный с развитием индивидов. Она существует только в форме реальной взаимосвязи индивидов, и в этом выражает природу человека: человек формируется культурой, он же ее создает и преобразует в «высшем максимуме взаимодействующих сил» $[4$, c. 440$]$.

Культуре, таким образом, отводится свое, особое место в социальной среде, определяющееся ее отличиями и от государства, и от цивилизации. «Общий закон, управляющий всеми творениями», ... и выражающийся «в строе, определенном виде, особом существовании всего», царит также и в истории, и осуществляется, как указывает Гердер, культурой [4, с. 37]. Возрастающее внимание философии к изменяющейся «среде» («средам»), формирующей автономного суверенного субъекта, навсегда включает культуру в качестве одной из таких «сред» в социально-философскую и историко-философскую проблематику.

Особенно очевидным это становится в немецкой классической философии. Рассуждая в духе традиций Просвещения, Кант сохраняет «инструментальную» трактовку культуры. В его понимании культура создает соответствующие возможности, объективные и субъективные условия для развития способностей человека, и в этом смысле она инструментальна. В то же время, рассматривая культуру как средство реализации всех задатков и способностей человека-технических, прагматических и моральных, Кант разрывает ее абсолютную связь с познанием. Выявляя связь «мира природы» и «мира свободы» в способности суждения, Кант, тем самым, допускает их соединение только в субъекте, которому свойственна «способность ставить любые цели» [5, с. 464].

Саму постановку проблемы культуры в контексте природы и свободы, независимо от предложенных Кантом решений, можно считать еще одним «коперниканским переворотом», который ознаменовал кардинальные сдвиги в культурфилософской теории.

В этом же проблемном поле размышляет Гегель, в философской системе которого культура «узнаваема», прежде всего, по таким атрибутам человеческого существования, как творчество и свобода. Индивиды осваивают уже наличный мир исторических форм объективного 
и абсолютного духа, делая это объективное бытие своим личным состоянием. Преодолевая свойственное Канту противопоставление «природы» и «свободы», в сложных диалектических взаимопереходах Гегель раскрывает динамику культивируемого человеческого духа, который осуществляет себя в действительности.

Таким образом, эпоха Просвещения на завершающем этапе заметно меняет вектор философской мысли, переходя от негативного отношения к культуре как традиции к интерпретации ее как инструмента, преобразующего человеческий разум, раскрывающего творческие способности человека, управляющего историей. Культура становится значимым средством организации разумной человеческой деятельности, различных аспектов социальной действительности. В контексте линейных представлений о природной и социальной реальности вызревает парадигмообразующая идея о связи культуры и сознания.

Подобная тенденция прослеживается, прежде всего, в идеях немецкого романтизма (И. Гете, Ф.Шеллинг, Т. Гофман, Ф. Шлейермахер, В. Гумбольдт), который развивает предложенную Кантом символическую трактовку культуры.

Ф.Шлейермахер рассматривает символ в качестве формы, в которой разум выявляет общее в природном многообразии, позволяет соединиться миру необходимости и миру свободы.

Развивая идею о связи природы и культуры через символическую активность сознания субъекта, Гете пишет о том, что «каждый человек, сообразно своей организации, имеет собственную истину, которую только он может понять в ее интимных чертах. Кто достигает всеобщезначимой истины, не понимает себя» (цит. по: [11, с. 76]). Смещая философский интерес к постижению индивидуальности человека, Гете предвосхищает установку философии XX века-«общее» в человеке есть его индивидуальность и уникальность, формирующаяся в культуре.

Символ, выражающий сущность культуры, становится центром философской проблематики конца XIX - начала XX веков, позволяя сконцентрировать внимание на смысловом наполнении человеческой жизни, на проблематике, которую можно определить как экзистенциальную идею человека и культуры, органичность их бытия.

Изменения в проблематике вызывают необходимость смены принципов и методологии философствования, которые в большей степени соответствовали познанию объективной (природной и социальной) реальности, но не субъекта. Это происходит на фоне формирования неклассической европейской науки, в которой распространяются идеи 
относительной истинности теорий и картин природы, выработанных в естествознании, зависимости объективно-истинного знания от средств и операций познавательной деятельности, от познающего субъекта, возникают предпосылки для создания целостной картины реальности через соотнесение внутринаучных и социальных ценностей и целей.

Возникшая дискуссия относительно общей методологии познания, а также различий между «науками о духе» и «науками о природе» (Г. Спенсер, В. Дильтей, Г. Зиммель, М. Вебер и др.), постепенно изменяет и подходы к исследованию культуры. С одной стороны, последователями О.Конта по образцу социологии создается наука о культуpe, призванная объединить ее теоретическое и эмпирическое изучение. Исследование культуры осуществляется через отыскание объективных законов ее возникновения и изменения, которые рассматриваются как одна из модификаций социальных законов, создающих и регулирующих социальный порядок. Причем, «представлялся этот порядок согласно доминирующим образцам того времени - моделям классической динамики, видевшим все изменения линейными, обратимыми, однозначно связанными с начальными условиями, предсказуемыми, независящими от случайности и подчиняющимися принципу детерминизма и каузальности» $[1$, с. 79$]$.

$\mathrm{C}$ другой стороны, формируется субъективистская парадигма социального познания, в которой создаются предпосылки для предельно широкого понимания культуры, возникает возможность связать культуру с любым «социальным действием», где есть смыслополагание и смыслопостижение (М. Вебер). В определенной степени этому способствовали и структуралистские трактовки культуры как всеохватывающей семиотической системы, совокупности разнообразных текстов, требующих анализа и прочтения. Различные социальные процессы начинают рассматриваться как формы «культуросозидающей активности». Формируется и изучается неклассическая социальная реальность - реальность человеческого сознания, процессов осмысления и кодирования. Возникает «горизонтальное» измерение культуры, раскрывающее многообразие как культурных форм, так и ее связей с социумом.

В рамках же философии культура остается одним из основных понятий, раскрывающих человеческую субъективность, специфику ее самочувствования и самоощущения во все более отчуждающемся обществе. В феноменологии Э.Гуссерля и В.Дильтея зарождается новая философская проблематика, в центре которой не объективные процессы возникновения социальной упорядоченности, а порядок, возни- 
кающий в сознании субъекта в процессе интерпретации социального мира $[1$, с. 80]. Субъект является частью мира (объектом), и одновременно конституирует мир своей смыслообразующей деятельностью. «Жизненный мир», «переживание», «понимание» отодвигают на второй план понятия классической парадигмы. Жизнь, мыслимая как поток, импульс, творческий порыв, не знает границы между субъектом и объектом, индивидуальным и коллективным. Любая индивидуализация в этом потоке уже сама по себе предполагает противоречие и абсурд, существование в «пограничной ситуации» между бытием и небытием, на границе хаоса и порядка.

Культура осмысливается как «персонализация» жизни, выделение из «жизненного мира» субъекта, создающего миф, язык, искусство, религию, и пытающегося самоопределиться в изначально чуждом мире. Исходя из символической сущности культуры, философия идет по пути анализа ее «вертикального» измерения, устанавливающего, что в глубинах культуры (глубинах сознания) находятся истоки жизни и смерти, творчества и разрушения и возникают предпосылки соединения сознания и бытия.

Включенность в познаваемую реальность субъекта наделяет эту реальность нелинейными характеристиками. В ней царит спонтанность, непредсказуемость, плюральность; множество свободно действующих субъектов представляют угрозу для социального порядка, который изначально враждебен стремящейся к самовыражению индивидуальности. Творимая индивидом, но принадлежащая социальному бытию, культура получает противоречивые трактовки.

$\mathrm{B}$ «философии жизни» культура амбивалентна - это отчужденная от человека система принудительной индивидуализации, одновременно и рождение и смерть индивидуальности (З. Фрейд); в культуре человек одновременно и завоевывает мир и защищается от него (О. Шпенглер). А.Шопенгауэр рассматривал культуру как способ религиозно-этического преодоления жизненной стихии; Ницше - как средство творческого жизнеутверждения, спасения человечества от вырождения и гибели.

Экзистенциализм отстаивает идею об органичности бытия человека и культуры, поскольку только в культуре человек может противостоять «вещному бытию». Ортега-и-Гассет, противопоставляя индивида «человеку-массе», «фиксирует» его в культуре, в исторических обстоятельствах, «удерживать» которые и означает обрести индивидуальность. К. Ясперс определяет культуру как способ преодоления открывшегося трагизма бытия, условие истинного существования че- 
ловека. В мире абсурда, тоски, тревоги и смятения культура становится спасительной «нитью Ариадны», прокладывающей путь уникально-неповторимой личности. Из инструмента, развивающего человека, культура трансформируется в его экзистенцию, жизненный мир, в котором человеческая индивидуальность не обезличивается под давлением «ничто», а получает возможность свободного существования.

Бытие человека в культуре обретает черты, особенно близкие к синергетическим ассоциациям, в постструктурализме. Культура представлена как нелинейное, многомерное пространство, в котором сочетаются и спорят друг с другом различные виды языка, ни один из которых не является исходным. Человек занимает непостоянную область на границе осмысленного и непознаваемого, принадлежит хаотической изменчивости, упорядочить которую можно, по выражению Делеза, через «хаоидное состояние»- мысль и творение. Действуя через глубины сознания субъекта, культура становится игрой смыслов, их смещений и трансформаций. Только принадлежа культуре, человек освобождается от угрозы исчезновения субъективности.

Аналогии с синергетикой просматриваются и в философии истории, в идеях цикличности мировых процессов, неповторимости всего возникающего в истории, отсутствия единого «центра» развития человечества (О. Шпенглер, А. Тойнби, К. Ясперс, П. Сорокин). Культура в этой цикличности становится «субъектным» аспектом истории, придающим ей направленность через смысложизненный поиск индивида. При этом именно «забвение экзистенциальных глубин личности» является, по словам К. Ясперса, причиной кризисов в непрерывном историческом движении.

Современное философское познание, открыв индетерминистский, плюралистичный, вероятностный характер человеческого бытия, снова оказалось перед решением вопросов: как возникает «рукотворный» порядок, как согласуются в нем индивидуалистические и коллективистские устремления, что определяет направленность социальных изменений. Смещенные синергетикой акценты в сторону не-стабильности, не-равновесности, не-устойчивости, не-линейности развития, выЗывают необходимость выявления в социальном бытии универсалъного источника социального самодвижения, который создает возможность индивидуального развития, организует и направляет развитие социума, согласовывает индивидуальное и коллективное и, как результат, сдерживает социальный хаос и создает социальный порядок.

Генезис культурфилософских идей, в общем виде представленный в данной статье, позволяет рассматривать в качестве такого источни- 
ка культуру, благодаря которой многочисленные и разнокачественные проявления человеческого бытия образуют самоорганизующуюся щелостность.

\section{1 Литература}

[1] Бевзенко Л.Д. Социальная самоорганизация. Синергетическая парадигма: возможности социальных интерпретаций. - К.: Ин-т социологии НАНУ, 2002.

[2] Богомолов A.C. Античная философия. - М.: Изд-во Моск. ун-та, 1985.

[3] В поисках нового мировидения: И. Пригожин, Е. и Н. Рерихи. М.: Знание, 1991.

[4] Гердер И.Г. Идеи к философии истории человечества.-M., 1977.

[5] Кант И. Соч.: В 6 т. Т. 5.-М., 1996.

[6] Лосев А.Ф. История античной эстетики. Ранний эллинизм.- М.: Искусство, 1979.

[7] Мень А. Христианство. Лекция, прочитанная в Московском доме техники 8 сентября - в вечер накануне гибели // Лит. газета. 1990. - 19 декабря. - № 51.- С. 5.

[8] Muхайлов A.B. Хейзинга в историографии культуры // Хейзинга. Осень средневековья.- М., 1988.

[9] Монтень М. Опыты. Кн. І. - М.; Л., 1954.

[10] Монтень М. Опыты. Кн. III. - М.; Л., 1954.

[11] Свасъли K.А. Иоганн Вольфганг Гете.-М., 1989.

[12] Столович Л.Н. Красота. Добро. Истина. Очерк истории эстет. аксиологии. - М.: Республика, 1994. 